\title{
Bhutan: environmental education and Gross National Happiness (GNH)
}

\author{
Tetsuro Matsuzawa ${ }^{1,2,3}$
}

Published online: 28 February 2019

(C) Japan Monkey Centre and Springer Japan KK, part of Springer Nature 2019

I visited the Kingdom of Bhutan (Druk Yul, the land of the dragon) for an audience with His Majesty the 4th King, Jigme Singye Wangchuck (Fig. 1). He is known for coining the term "Gross National Happiness," GNH. Bhutan is a small country in the Himalayas. It is sandwiched between two huge countries, China in the north and India in the south. The elevation is as low as $200 \mathrm{~m}$ altitude continuing to the Indo-Gangetic Plain, and as high as $7500 \mathrm{~m}$ in the Bhutan Himalayas. The highest point is Mt. Gangkar Punsum $(7564 \mathrm{~m})$, the untrodden peak. The abundant water flowing down from the Himalayan glaciers gives Bhutan a rich resource for hydroelectric power generation. The electricity is sold to India and represents a major source of foreign trade income for the country.

The latitude of Bhutan is $27^{\circ} 47^{\prime}$ North at the capital, Thimpu. This is equivalent to Okinawa in Japan, and a little to the north of Miami, Florida. The size of the country is $38,390 \mathrm{~km}^{2}$ - slightly larger than Kyushu island in Japan, and slightly smaller than Switzerland. The population is 807,600, according to World Bank statistics from 2017. About $80 \%$ of the people belong to ethnic groups of Tibetan origin, while the remaining $20 \%$ are Nepali. The native Bhutanese language is called Dzongkha. It is written using the Tibetan alphabet, but can be transcribed by the western alphabet as well. English is also used as a public language.

I loved climbing mountains when I was young (Matsuzawa 2016). I reached the summits of Muztagh Ata (7509 m) in Eastern Pamir near the Taklamakan Desert in 1989, and Shishapangma $(8027 \mathrm{~m})$ in Tibet in 1990 . Then I shifted the focus of my exploration from the vertical to the horizontal: I wanted to learn more about the full expanse of the

Tetsuro Matsuzawa

matsuzawa.tetsuro.8w@kyoto-u.ac.jp

1 Kyoto University Institute for Advanced Study, Kyoto, Japan

2 Primate Research Institute, Kyoto University, Inuyama, Japan

3 Japan Monkey Centre, Inuyama, Japan

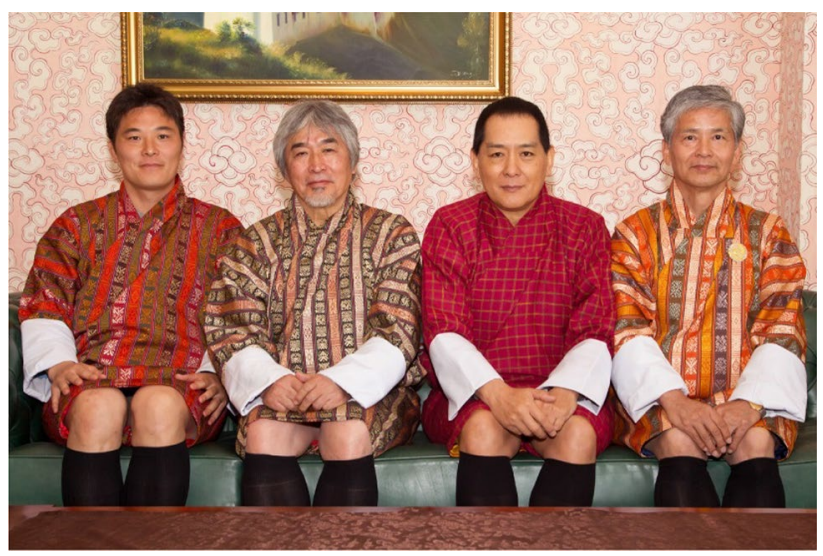

Fig. 1 We had an audience with His Majesty the 4th King Jigme Singye Wangchuck on November 23rd 2018. From left to right: Ryota Sakamoto, Juichi Yamagiwa, His Majesty, and Tetsuro Matsuzawa (photo provided by His Majesty JSW, the Kingdom of Bhutan)

Himalayan area. I went to Hunza Valley, Yunnan China, and Bhutan in three consecutive years. First I went to Hunza Valley in Karakorum, Pakistan, in 1993. Hunza Valley is the corridor connecting the East and the West, used by Marco Polo in the thirteenth century. I went to see the Mongolian people living in Yunnan, China in 1994, and was amazed at how they succeeded in maintaining their traditional Mongolian way of life so deep in the south of China. The place was also close to the Meili Snow Mountains (6740 m), located at the southern limit of the Himalayas (Matsuzawa 2017). Finally I reached Bhutan for the first time in October 1995.

Beginning in the 1990s, primatologists began to pay attention to the existence of culture and cultural traditions in wild chimpanzees (Biro et al. 2003; Matsuzawa 1994, 2001; Whiten et al. 1999). I found myself paying attention more and more to human cultural variation alongside that of chimpanzees. I wanted to know how people kept their traditional way of life in Hunza Valley, Yunnan, and also in Bhutan. Our theory of "Education by Master-apprenticeship" 


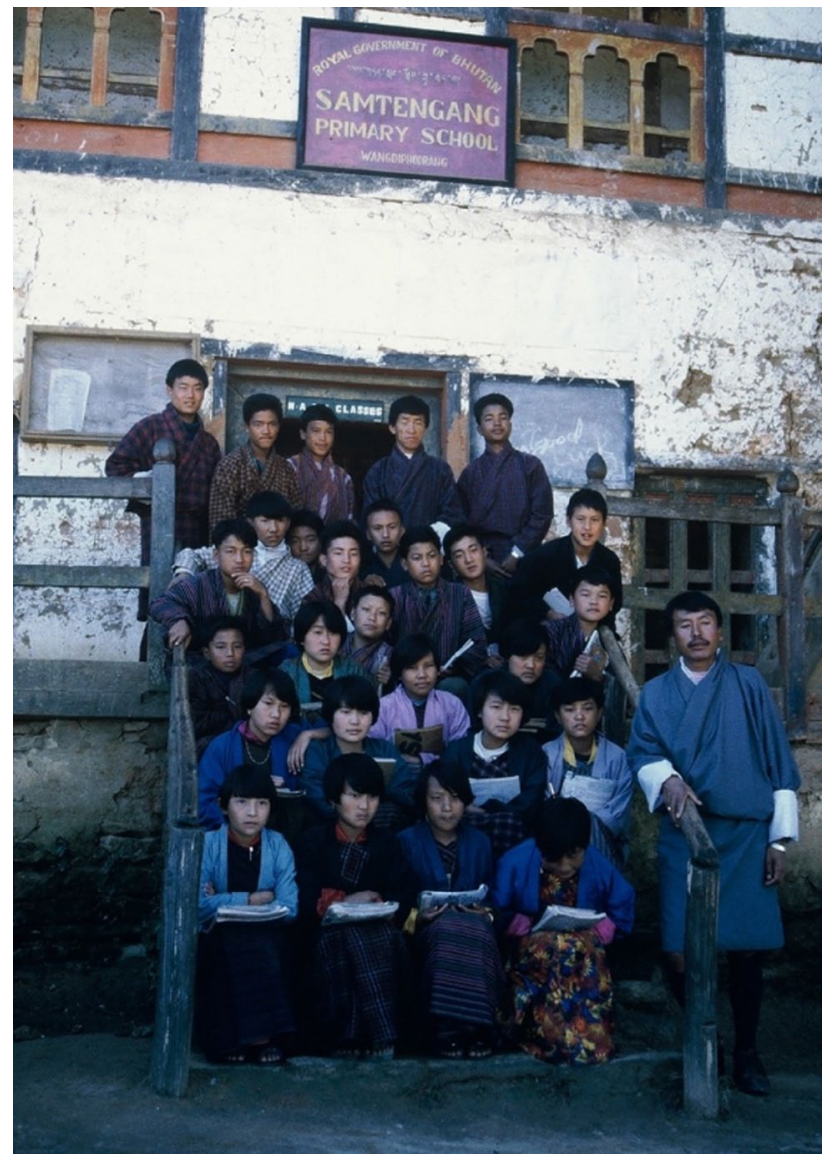

Fig. 2 Pupils at Samtengang Primary School in October 1995 (photo taken by Akira Demizu)

(Matsuzawa 2001), based on the mother-infant relationship in chimpanzees, predicts that family life and primary education must have key roles in the transmission of culture from one generation to the next in human societies. During my trips to Bhutan, I visited several primary schools (Figs. 2, 3).

Kyoto University and Bhutan have a long-running friendship. It began in November 1957 when Her Majesty the 3rd Queen (the royal grandmother), Ashi Kesang Choden Wangchuck, visited Kyoto (Fig. 4). There was no diplomatic relationship between Bhutan and Japan at the time. Therefore, the Japanese government made no special effort to receive the royal visitor.

Instead, a Kyoto University professor, the late Takeo Kuwabara (1904-1988) took the opportunity to welcome Her Majesty. He guided her through Kyoto during the beautiful autumn season, as leaves were turning red and yellow. Professor Kuwabara had a special hope: to climb the untrodden peaks of the Bhutan Himalayas. He was the spiritual twin of Kinji Imanishi (1902-1992); the two scholars graduated together from the same secondary school, high school, and Kyoto Imperial University at the same time. They wanted to do pioneering work and founded the Academic

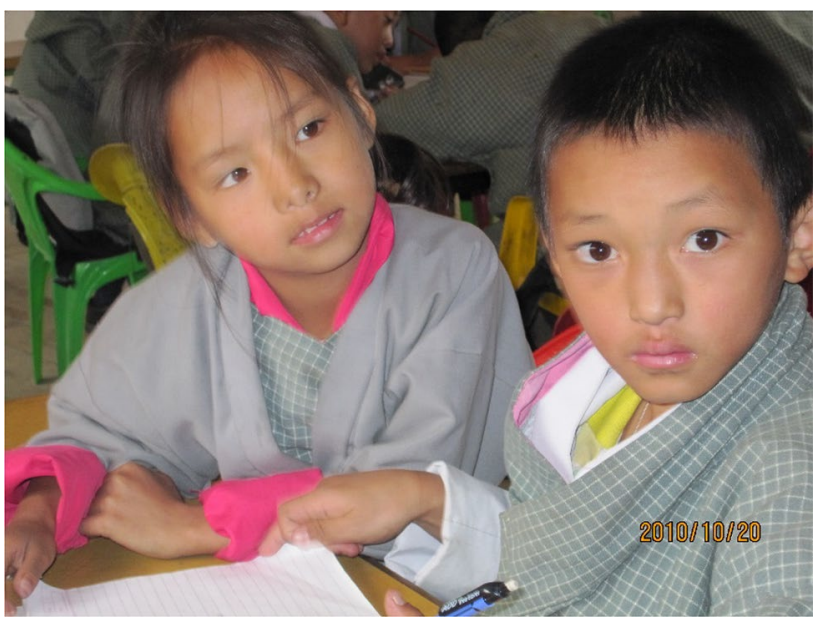

Fig. 3 A girl helping a boy with school work at Paro Primary School in October 2010 (photo taken by Tetsuro Matsuzawa)

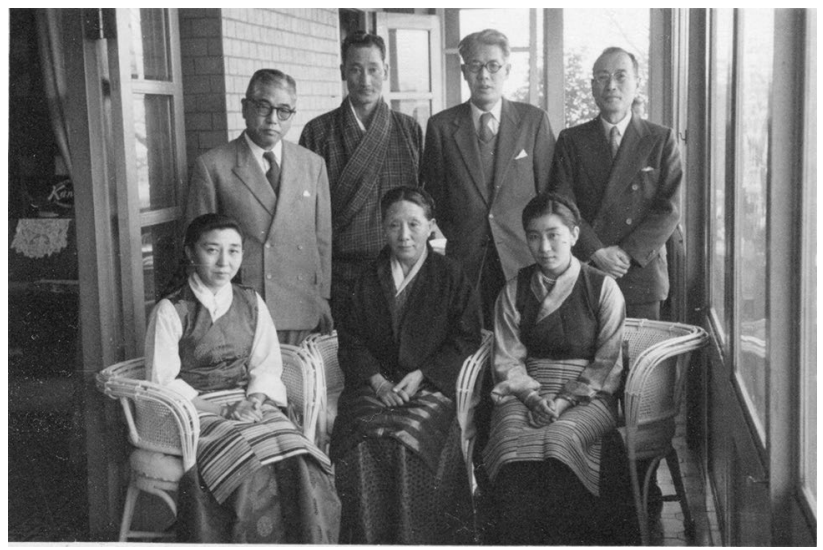

Fig. 4 Her Majesty the 3rd Queen (the royal grandmother), Ashi Kesang Choden Wangchuck (front row, right), visited Kyoto in November 1957. She was welcomed by Prof. Takeo Kuwabara (back row, second from right) (Photo provided by AACK)

Alpine Club of Kyoto (AACK). AACK consists of the graduates of Kyoto University Alpine Club (KUAC), which has only undergraduate students as members. Shortly after his meeting with Her Majesty, in January 1958, Professor Kuwabara became the 3rd President of AACK. (By the way, Imanishi was the 4th president and I am the current 14th president of AACK.) He led an expedition to Mt. Chogolisa (7654 m) in Karakorum, Pakistan, and successfully completed its first ascent on August 4, 1958. In the same year, Imanishi and his student Jun'ichiro Itani (1926-2001) went to Africa to establish study sites for wild gorillas and chimpanzees. Since then, AACK continued in its efforts to foster exchanges with Bhutan. Years later, in 1985, a KUACAACK joint expedition finally achieved the first ascent of 


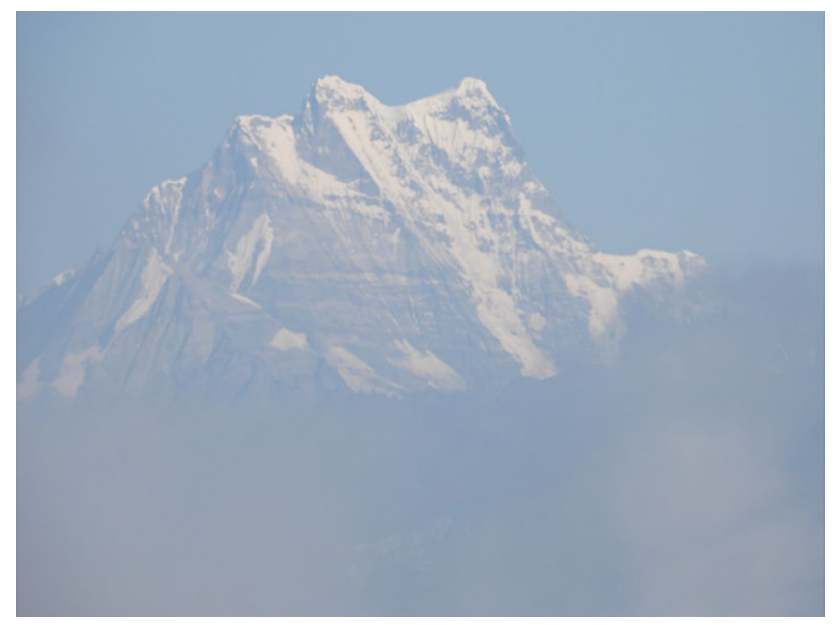

Fig. 5 A KUAC-AACK joint expedition successfully completed the first ascent of Masang Gang (7194 m) of the Bhutan Himalayas (photo taken by Tetsuro Matsuzawa on Nov 21st 2018)

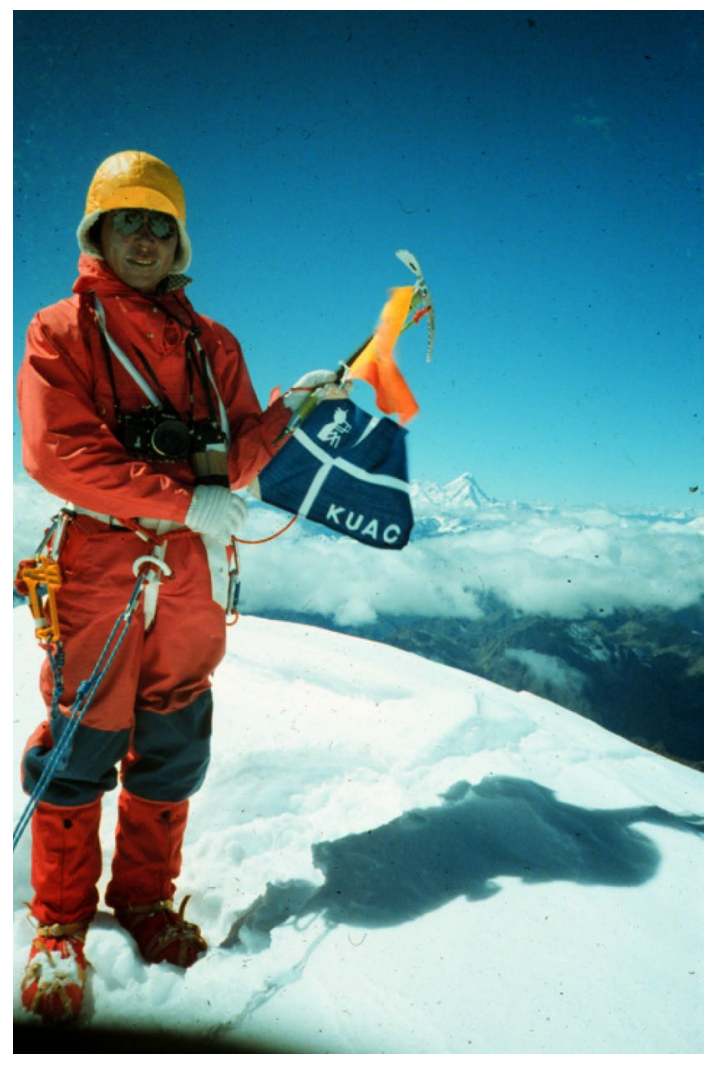

Fig. 6 A Kyoto University Alpine Club (KUAC) and Academic Alpine Club of Kyoto (AACK) joint team reached the summit of Masang Gang (7194 m) on October 13, 1985. The members stopped climbing several meters before reaching the summit, showing respect to the untrodden peak and to the religious beliefs of the local people (photo provided by KUAC and AACK)
Masang Gang (7194 m) in the Bhutan Himalayas (Figs. 5, $6)$.

I was also charmed by the Bhutan Himalayas ever since my entrance to Kyoto University and KUAC in 1969. My colleagues and friends of the mountaineering club went to Bhutan, and, what's more, they accomplished the first ascent. I visited Bhutan in 1995, but for many years had no opportunity to return to the country. Then, Kyoto University approached me about organizing an international social outreach program. The idea was as follows. The university should identify a suitable country and promote mutual understanding between it and Kyoto University. I had no hesitation in recommending Bhutan. There were three reasons. First, the long history of its association with Kyoto University provided an excellent basis for such efforts. Second, the size of the country is relatively small and so seemed like a good fit with a university that consists of about 3000 professors and 23,000 students. Finally, I saw a traditional way of life there that reminded me of old-time Japan: for example, the Bhutanese national dress is reminiscent of Japanese traditional wear, the kimono.

I visited Bhutan four times: in 1995, 2010, 2013, and 2018. I had the opportunity to have an audience with His Majesty the 4th King twice, in 2010 and 2018. The first meeting, in 2010, made me decide to launch a new social outreach endeavor called "Kyoto University Bhutan Friendship Program (KU-Bhutan)" (see https://www.kyoto-bhutan.org/ index-e.html). KU-Bhutan, created with Prof. Kozo Matsubayashi, has sent 17 missions to Bhutan in the past 9 years; many Kyoto University faculty members, staff and students have thus had opportunities to experience this charming country. Through direct conversations with the 4th King, I learned the story behind the concept of "Gross National Happiness" and his views on how best to govern a country.

His Majesty Jigme Singye Wangchuck was born on November 11th 1955. He became the 4th King in 1972, at the age of 16 years when his father, the 3rd King, suddenly passed away. His Majesty coined the term Gross National Happiness (GNH) as the key concept for governing a country. At first he used the word "Contentedness": how content people were with their daily lives. Then he changed it to "Happiness". "Happiness" is more abstract, broader, and more appealing than "Contentedness".

Article 9 of the Japanese Constitution declares the country's renunciation of war. Article 9 says "Aspiring sincerely to an international peace based on justice and order, the Japanese people forever renounce war as a sovereign right of the nation and the threat or use of force as means of settling international disputes". Article 9 of the Constitution of the Kingdom of Bhutan happens to be GNH. Bhutan's Article 9 says "The State shall endeavor to apply the Principles of State Policy set out in this Article to ensure a good quality of life for the people of Bhutan in a progressive and prosperous country that is committed to peace and amity in the world. 
The State shall strive to promote those conditions that will enable the pursuit of Gross National Happiness".

His Majesty Jigme Singye Wangchuck first formulated the idea of GNH in the 1970s, when he was still very young. He then promoted the drafting of a constitution, which was enacted in 2008, and reformed the country from monarchy to constitutional monarchy. I posed the question to him: "Why did it take such a long time for Bhutan to get a constitution?" His answer was: "I have been waiting for literacy rates to go up". Without high literacy rates through good primary education, people cannot read the constitution. He had concentrated on enriching the entire country's primary education, then waited until literacy rates had exceeded $60 \%$.

I asked: "What is important for governing the country?" He said: "It is Wisdom, Power and Compassion." We can easily understand why "Wisdom" and "Power" are important for a leader, but it took me a while to understand the meaning of "Compassion" in this context. In the original Latin, "compassion" comes from "com" (together) plus "pati" (patient). Compassion is therefore the attitude of being patient together with the people. In short, it might be Love.

I thought that it could not have been an easy job being the king of a country for decades. However, he said: "I have never experienced stress." I was very surprised, and asked: "Why? Why did you never experience stress?" Then he said "Mindfulness." I was a little surprised again to hear the word. "Mindfulness" is a very contemporary term in psychology, whose meaning is difficult to explain. Roughly, through a sort of meditation, you can reach a state called mindfulness. For me, in short, it means the mind that monitors the mind. You can see your mind just as you see your own body.

His Majesty was very charming. My most recent meeting with him was held in his palace on November 23, 2018. I was with President Juichi Yamagiwa of Kyoto University. This was the first time for His Majesty to meet President Yamagiwa. His Majesty started the conversation as follows: "President, I know that you are a researcher of gorillas. I know that Matsuzawa is a researcher of chimpanzees. However, we also have apes in Bhutan." I was very puzzled! There are monkeys and langurs in Bhutan, but no apes at all. He continued: "We have snow men in Bhutan." He told us that he had seen their skulls and foot-prints, and believes in their existence deep in the Bhutan Himalayas. He continued by saying: "Camera traps may help us capture images of these snow men".

For the visit, we also put together a photo book entitled "Memories of the sacred kingdom," as a gift. The book commemorates the 60th anniversary of the friendship between Kyoto University and Bhutan (Fig. 7). He stopped at the page of Mt. Masang Gang, the snow mountain. He asked, "Did you reach the summit?" I said, "My colleagues from Kyoto University succeeded in the first ascent, but they

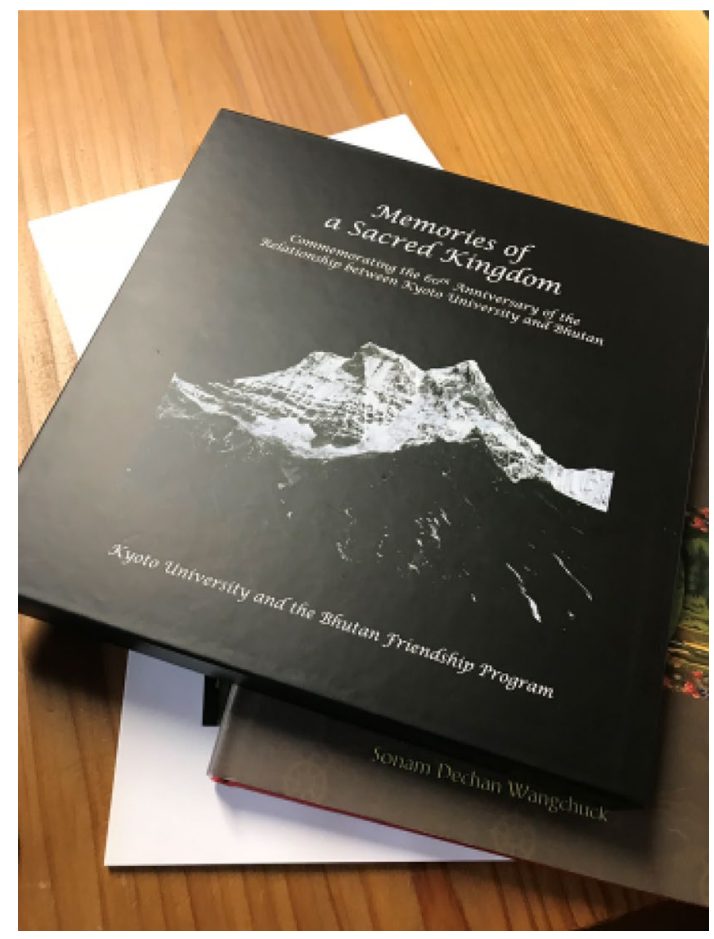

Fig. 7 The photo book entitled "Memories of the Sacred Kingdom," prepared as a gift. The book commemorates the 60th anniversary of the friendship between Kyoto University and the Kingdom of Bhutan

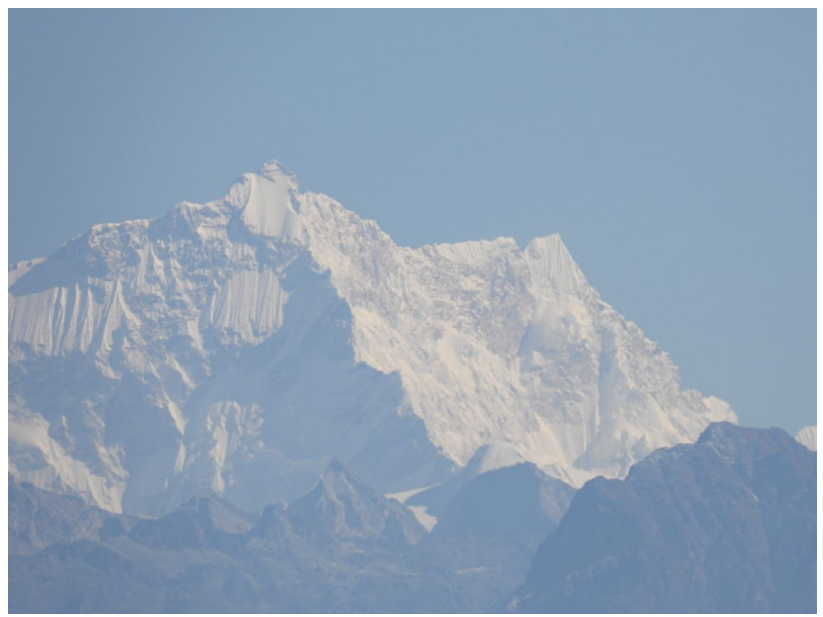

Fig. 8 Gangkar Punsum (7564 m), the untrodden highest peak in Bhutan (photo taken by Tetsuro Matsuzawa on November 21st 2018)

actually stopped several meters short of the real summit. This was to show respect to the local people and their religious beliefs about the sacred mountains." As His Majesty looked through the photos of the mountains, he said, with a smile, "I also want to go to the snow peak." Of course, I know that it was in jest. I replied, also smiling, "I would like to become your eyes to climb the mountains and to see the 
real snow men." I wish I could go to Gangkar Punsum to look for the snow men (Fig. 8).

Primary education in Bhutan is unique in several respects. First, in pre-primary school-corresponding to kindergarten age-pupils start to learn English. English is also the language of instruction in primary schools. There are three major subjects that pupils are taught every day in school: Dzongha, English, and environmental education. How to define and how to teach GNH is still controversial. See the detailed report on GNH: ISBN 978-99936-14-86-9 (Centre for Bhutan Studies \& GNH Research 2016). The most recent survey on GNH in 2015 contains 9 domains and consists of 148 questions. However, observing primary school classes gave me some ideas. The school was kept clean. The school yard was also kept clean, and it was the place to put environmental education into practice. From your backyard you can make a change. Environmental education in Bhutan seems to be synonymous with teaching the ideas and underlying values of GNH through everyday practice.

In my understanding, the core part of the idea of GNH lies neither in the domains nor the questions, but in the following calculation. GNH can be expressed as a fraction: the numerator is richness while the denominator is desire. Happiness can be defined by dividing the numerator by the denominator. You feel happy when you are rich enough as measured against your desire.

People in many advanced countries have been primarily pursuing richness, and more and more of it. GDP (Gross Domestic Product) and GNP (Gross National Product) are indices of richness: how many things you have, how many products, how much money, etc. However, as you become more rich, your desire increases too: as a result people continue to want more and more things, products, money, and so on. Thus, both the numerator and the denominator increase in parallel, such that the fraction (happiness) does not increase at all. In contrast, GNH suggests that you keep desire as small as possible. Suppose that you are moderately rich: the numerator is constant. Then you try to minimize your desire: the denominator decreases. Thus the fraction increases and you feel greater happiness.

Before the meeting with His Majesty the 4th King, we welcomed Her Royal Highness Princess Sonam Dechan Wangchuck to Japan a year ago, in October 2017. Her Royal Highness is a daughter of the 4th King and the younger sister of His Majesty the current 5th King Jigme Khesar Namgyel Wangchuck. HRH Princess came to attend the 60th anniversary memorial symposium of the friendship between Bhutan and Kyoto University (Fig. 9).

HRH Princess Sonam Dechan Wangchuck spent several years in the United States, graduating from Stanford and then Harvard University in law. I was curious to ask why she majored in this discipline. She told me that she wanted to help her father. The constitution was His Majesty's

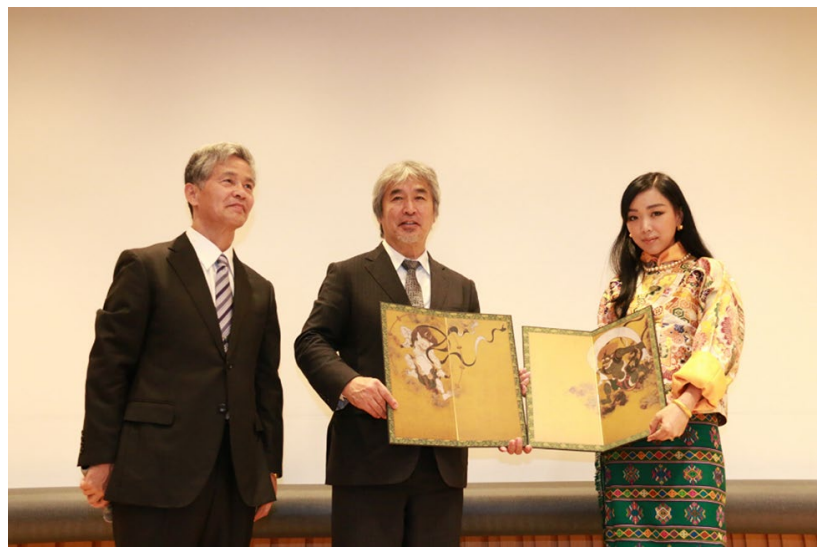

Fig. 9 Her Royal Highness Princess Sonam Dechan Wangchuck visited Japan a year ago, in October 2017, to attend the 60th anniversary memorial symposium of the friendship between Bhutan and Kyoto University (photo was taken on October 26th, 2017 and provided by the Kyoto University Bhutan Friendship Program)

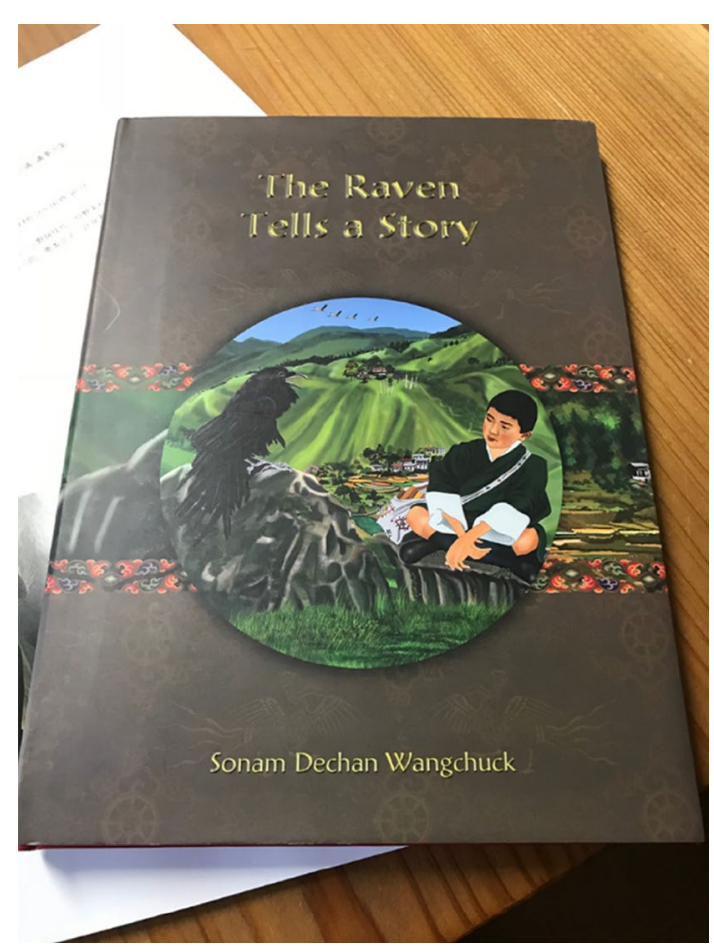

Fig. 10 The children's book entitled "The Raven Tells a Story" given to me by Her Royal Highness Princess Sonam Dechan Wangchuk (Photo taken by Tetsuro Matsuzawa)

contribution, but implementing it requires an elaborate legal system. The country needs judges, lawyers, public prosecutors, and so forth. HRH Princess has taken on the role of head at the JSW Law school, the first law school in the country. JSW Law is just in the process of building a new campus near Paro, close to the international airport. 


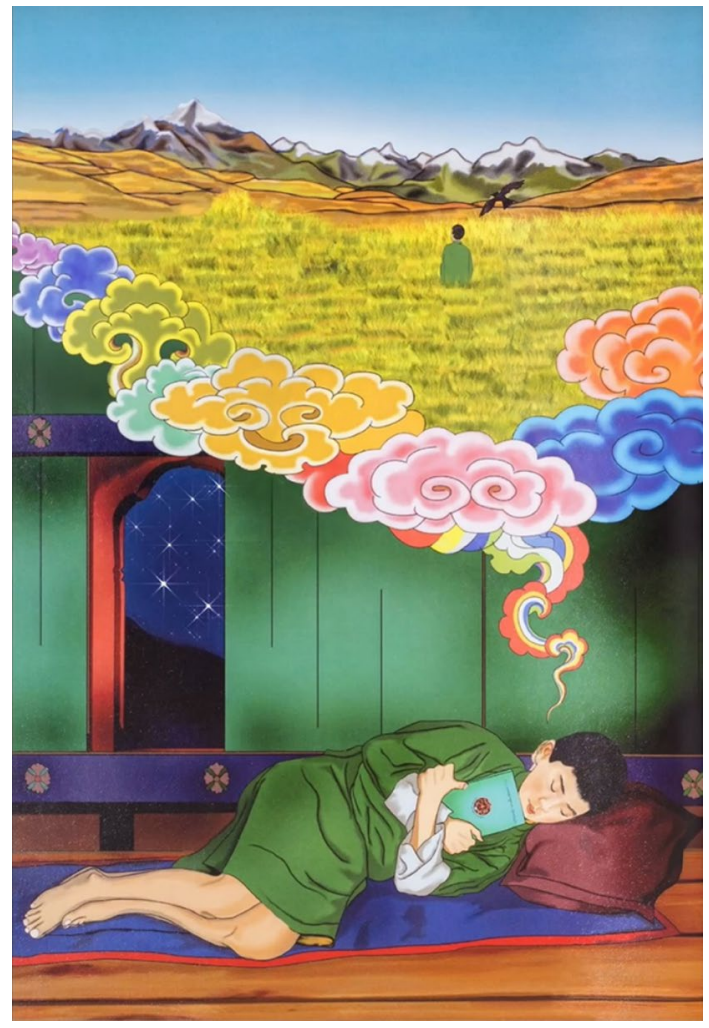

Fig. 11 Animated version of the children's book "The Raven Tells a Story". The book was written by HRH Princess Sonam Dechan Wangchuck. My colleagues at Kyoto University of Arts and Design (KUAD) produced an e-book version as well as the animation. (Photo taken by Tetsuro Matsuzawa)

When I met HRH Princess Sonam Dechan Wangchuck in Kyoto in 2017 she gave me a children's book entitled: "The Raven Tells a Story" (Fig. 10). The raven (from the genus Corvus) is the national bird of Bhutan. In the book, the raven tells a boy in primary school about the history of Bhutan, the importance of the constitution, and GNH. It is not an easy task to describe such complex matters, but the book is well written and easy to read. First, I asked my daughter, Yoko Sakai, to translate it into Japanese. The translation immediately convinced us of the importance of the book for young children in Bhutan. Japan is known as the country of animation, so Her Royal Highness asked if we could also produce an animated version of the book. Therefore, I asked my colleagues at Kyoto University of Arts and Design (KUAD) to develop an e-book version as well as an animation (Fig. 11). During the recent visit in 2018, we gave the animation to Her Royal Highness. We also made the materials freely available to the public (see https://www.kyoto-bhutan.org/index-e.html).
Our hope is that these materials made in Japan will reach the minds of young people in Bhutan. They may even start writing books or making animations themselves, for themselves and for their country. Through these grassroots efforts, I hope to touch the future of the Kingdom of Bhutan.

Acknowledgements I am grateful to His Majesty the 4th King Jigme Singye Wangchuck, who kindly gave me the opportunity for the interviews. I also thank Her Royal Highness Princess Sonam Dechan Wangchuck whom we welcomed for the visit to Kyoto University. Thanks are due to President Yamagiwa, Prof. Yuko Nishitani, Prof. Ryota Sakamoto, Ms. Emiko Kato, Ms. Mai Tatsuno, Mr. Kazuyoshi Matsui, Mr. Norimichi Matsunaga with whom I shared many nice experiences during the 17th mission to Bhutan in 2018. Special thanks are due to President Kazuo Oike of KUAD and his staff for making an animation and e-book of the children's book. I also thank friends in Bhutan who welcomed us, especially Mr. Karchung Wangchuk of Lohmen Tours who has helped me since the first visit in 1995. Without his kind arrangement it would have been impossible to have as pleasant a time in Bhutan as we did. Financial support for preparing the manuscript came from MEXT-JSPS grants \#24000001, \#16H06283; the Japan Society for the Promotion of Science (JSPS) Core-to-core Program CCSN, and the Leading Graduate Program of Primatology and Wildlife Science (U04) to the author. I also thank Dr. Dora Biro of Oxford University and Dr. James Anderson of Kyoto University for help with editing the English text.

\section{References}

Biro D, Inoue-Nakamura N, Tonooka R, Yamakoshi G, Sousa C, Matsuzawa $\mathrm{T}$ (2003) Cultural innovation and transmission of tool use in wild chimpanzees: evidence from field experiments. Anim Cogn 6:213-223

Centre for Bhutan Studies \& GNH Research (2016) A compass towards a just and harmonious society: 2015 GNH Survey Report. Centre for Bhutan Studies \& GNH Research, Thimphu, Bhutan, pp 1-340

Matsuzawa T (1994) Field experiments on use of stone tools by chimpanzees in the wild. In: Wrangham RW, McGrew WC, Waal FBM, Heltne PG (eds) Chimpanzee cultures. Harvard University Press, Cambridge, pp 351-370

Matsuzawa T (2016) Mountain day: isomorphism of mountaineering and science. Primates 57:441-444

Matsuzawa T (2017) Monkeys and mountains in Yunnan, China. Primates 58:379-383

Matsuzawa T, Biro D, Humle T, Inoue-Nakamura N, Tonooka R, Yamakoshi G (2001) Emergence of Culture in Wild Chimpanzees: Education by Master-Apprenticeship. In: Matsuzawa T (ed) Primate origins of human cognition and behavior. Springer, Tokyo

Whiten A, Goodall J, McGrew WC, Nishida T, Reynolds V, Sugiyama Y, Tutin CEG, Wrangham RW, Boesch C (1999) Cultures in chimpanzees. Nature 399:682-685

Publisher's Note Springer Nature remains neutral with regard to jurisdictional claims in published maps and institutional affiliations. 